\title{
Comprehensive assessment of the association between estrogen receptor of alpha polymorphisms and the risk of prostate cancer: evidence from a meta-analysis
}

\author{
Guang $\mathrm{Li}^{1, *}$, Meng Yang ${ }^{2, *}$, Xian $\mathrm{Li}^{3}$ and Shixiong Deng ${ }^{1}$ \\ ${ }^{1}$ Laboratory of Forensic Medicine and Bioinformatics, Chongqing Medical University, Chongqing, China \\ ${ }^{2}$ Research Department, Children Hospital of Chongqing Medical University, Chongqing, China \\ ${ }^{3}$ Laboratory of Biomedical Engineering, Chongqing Medical University, Chongqing, China \\ "These authors contributed equally to this work \\ Correspondence to: Xian Li, email: lixian810@gmail.com \\ Shixiong Deng, email: dengshixiong1963@163.com
}

Keywords: estrogen receptor of alpha, polymorphisms, prostate cancer, meta-analysis

Received: June 22, $2017 \quad$ Accepted: August 27, $2017 \quad$ Published: September 21, 2017

Copyright: Li et al. This is an open-access article distributed under the terms of the Creative Commons Attribution License 3.0 (CC BY 3.0 ), which permits unrestricted use, distribution, and reproduction in any medium, provided the original author and source are credited.

\section{ABSTRACT}

We performed a meta analysis to access the relationship of estrogen receptor of alpha (ESRa) polymorphisms with the risk of prostate cancer (PC). Twenty-four casecontrol studies (including 5477 cases and 10708 controls) were recruited for metaanalysis. The strongest association with the risk of PC was observed between ESRa rs9340799 and rs2234693 under the two genotypic models of allele and codominance in the overall population $(p<0.05)$. Under the subgroup analysis of ethnicity, we observed that ESRa rs9340799 was significantly associated with the susceptibility to $\mathrm{PC}$ in European population (AvsG, $p=0.000$; AAvsGG, $p=0.002$ ), while there was no difference in Asian (AvsG, $p=0.493$; AAvsGG, $p=0.736$ ) or African population (AvsG, $p=0.800$; AAvsGG, $p=0.788$ ). The results also showed that significant association between rs2234693 and the susceptibility to PC in European (CvsT, $p=$ 0.004; CCvsTT, $p=0.001$ ) and Asian population (CvsT, $p=0.004$; CCvsTT, $p=0.003$ ), but not in African population (CvsT, $p=0.636$; CCvsTT, $p=0.669$ ). The meta-analysis indicated that ESRa rs9340799 and rs2234693 might contribute to susceptibility and development of PC in European population.

\section{INTRODUCTION}

Prostate cancer (PC) is a common malignant tumor occurring in males and has become the predominant cause of death among males, which accounts for about $10 \%$ of male mortality [1]. However, the pathogenesis of PC remains to be determined. Several studies reported that both genetic susceptibility and environmental factors such as diet and lifestyle exerted major influences on the occurrence of PC [2]. In particular, single nucleotide polymorphism (SNP) derived from single nucleotide point mutation was considered to be one of the important material carriers with genetic susceptibility [3]. As the third generation genetic marker, SNP was polymorphic and derived from the variation of individual nucleotide at the same site of DNA sequence. Due to the diversity in diet, geological areas and genetic factors, the incidences of PC among races remained differences and similarities. Estrogen receptor of alpha $(\operatorname{ESR} \alpha)$, found by Jensen in 1971, was an estrogen-dependent transcription factor, and located at the Zone 1, Area 25 of long-arm of the No. 6 chromosome (6q25.1), and the polymorphic sites of its intron and exon areas had been already identified [4]. Meanwhile, as a member of nucleus receptor superfamily, ESR $\alpha$ could transfer into nucleus of PC cells in combination with estrogen, regulate the signal pathways of gene transcription and promote cell proliferation [5]. Currently, A number of anti-cancer drugs play important roles in disturbing and hindering the combination of the nodes to achieve the therapeutic goal [6]. It is possible that the development of PC may be affected by the SNP site of ESR $\alpha$. However, the results were not always consistent 
[9-12]. Different regional and ethnic groups varied from inherit susceptibility genes and SNPs due to the highly genetic heterogeneity of PC.

Although there are several studies on investigating the interactions between ESR $\alpha$ and PC among Asians, Europeans and Africans [7, 8], the inconsistency of findings exists. Remarkably, both sites of rs9340799 and rs2234693 have been widely studied in ESR $\alpha$ genetic polymorphisms [9-12], but ESR $\alpha$ rs9340799 or rs2234693 were independent of PC susceptibility because of quality and quantity limitations. The meta-analysis of ESR $\alpha$ rs9340799 and rs2234693 was firstly conducted by Ding [10] in 2012, indicating that rs9340799, not rs2234693, confered an elevated risk of PC. Gu's study [11] demonstrated that there was no significant difference between 4,884 case groups and 10,134 control groups in rs2234693 regardless of allele or other models (allele model, $\mathrm{OR}=0.98 ; 95 \% \mathrm{CI}, 0.88-1.08 ; P=0.685$; dominant model, OR $=0.98 ; 95 \%$ CI, 0.89-1.07; $P=0.685$; recessive model, OR $=0.96 ; 95 \%$ CI, $0.81-$ $1.14 ; P=0.657$; homozygous model, $\mathrm{OR}=0.96 ; 95 \%$ CI, 0.77-1.19; $P=0.708$; heterozygous model, OR = 0.96 ; $95 \%$ CI, 0.81-1.13; $P=0.708$, respectively). On the other hand, $G$ in rs9340799 may be related to PC susceptibility (allele model, OR $=1.09 ; 95 \% \mathrm{CI}, 1.03-$ $1.17 ; P=0.006$; dominant model, $\mathrm{OR}=1.17 ; 95 \% \mathrm{CI}$, $1.07-1.29 ; P=0.001$; homozygous model, $\mathrm{OR}=1.17 ; 95$ $\%$ CI, 1.01-1.35; $P=0.040$; respectively), especially in Africans (allele model, OR $=1.53 ; 95 \%$ CI, 1.13-2.07; $P=0.006$; dominant model, $\mathrm{OR}=1.78 ; 95 \% \mathrm{CI}, 1.19$ 2.66; $P=0.005$; homozygous model, $\mathrm{OR}=2.04 ; 95 \%$ CI, $1.00-4.14 ; P=0.049$, respectively). In contrast, such connections had not been indentified yet in Europeans or Asians, as reported in Ding's publications. Fu's research[9] presented that rs 9340799 polymorphism was significantly associated with $\mathrm{PC}$ in overall populations $(\mathrm{GG}+\mathrm{GA}$ vs. AA: $\mathrm{P}=0.002$; G vs. A: $P=0.004)$, Caucasians $(\mathrm{GG}+\mathrm{GA}$ vs. AA: $P=0.008$; $\mathrm{G}$ vs. A: $P=0.016$ ) and Africans (GG+GA vs. AA: $P=0.005$; G vs. A: $P=0.006$ ), but not in Asians (GG+GA vs. AA: $P=0.462$; G vs. A: $P=$ $0.665)$. Another study [12] regarding 4,623 cases of PC patients pointed out that rs2234693 in overall populations was markedly involved in PC susceptibility $(P<0.05)$, and the polymorphism CC may increase the risks of PC. Moreover, ethnic subgroup analysis revealed that the site had a close correlation with Europeans $(P<0.05)$, but not with Asians or Africans $(P>0.05)$.

It has been shown that there is certain correlation between PC susceptibility and ESR $\alpha$ rs9340799 or rs2234693, but unanimous conclusion has not been reached yet in the repetitive studies. Therefore, it remains to be verified further. This study aims to assess the association of ESR $\alpha$ sites rs9340799, rs2234693 and the susceptibility of PC according to all published literatures using Cochrane system assessment method. These findings will provide reliable evidence for therapeutic approahes in PC disease.

\section{RESULTS}

\section{Studies included in the meta-analysis}

In the meta-analysis, totally 112 relevant articles were obtained under some fundamental restrictions. After filtering, 24 eligible articles [14-37] were finally selected on the basis of the inclusion and exclusion criteria. The flow chart of selecting articles process was presented in Figure 1. Therefore, there were 41 independent casecontrol studies in total, and the genotype distribution of control group was based on Handy-Weinberg. For ESR $\alpha$ rs9340799, there were 17 studies involving a total of 3960 PC cases and 4848 normal controls. For ESR $\alpha$ rs2234693, 24 studies (5477 PC cases and 10708 normal controls) were available, respectively. The main characteristics of these included studies were shown in Table 1.

\section{Meta-analysis results}

ESRa rs9340799 polymorphism and susceptibility to PC. To assess the association of ESR $\alpha$ rs 9340799 polymorphism with PC, 17 studies were included in this meta-analysis with 3960 PC cases and 4848 normal controls (Table 2). Both allele and additive models were tested in the overall population. PC susceptibility in Caucasian population showed strong association in the allele model (AvsG), and patients carrying mutant gene A were 0.84 times incidence rate of susceptibility to $\mathrm{PC}(\mathrm{OR}=0.84,95 \mathrm{CI} \%: 0.72-0.96, P=0.000)$. In the additive model (AAvsGG), PC case group obtained 0.75 times of probability on AA genotype and enhanced the risk of disease ( $\mathrm{OR}=0.75,95 \% \mathrm{CI}, 0.56-1.00, P=0.002)$. In contrast, there was no significant association between Asian and African populations in all the models. Detailed results were listed in Table 2. Test of heterogeneity in the other models (AAvsAG+GG, AA+AGvsGG, AGvsGG) were not significant among different races of populations.

ESRa rs2234693 polymorphism and susceptibility to $P C$. There were 24 studies with $5477 \mathrm{PC}$ cases and 10708 normal controls in this meta-analysis to evaluate the association of ESR $\alpha$ rs 2234693 polymorphism with PC (Table 2). In allele model, the risk genotype of wild type $\mathrm{T}$ was used to assess the relationship between $\mathrm{C}$ gene mutation and susceptibility to PC. Our results showed that there was statistical heterogeneity among these studies $\left(\mathrm{I}^{2}=56.75, P=0.003\right)$, so the random effects model was chosen for meta-analysis. As shown in Figure 2 and Figure 3, forest maps presented that PC patients carrying $\mathrm{C}$ genotype got a higher risk than people with T genotype (OR $=1.09,95 \%$ CI:1.00-1.18, $P=0.000)$, especially in the European $(\mathrm{OR}=1.11,95 \%$ CI:1.00-1.23, $P=0.004)$ and Asian populations (OR $=$ $1.02,95 \%$ CI:0.86-1.21, $P=0.004)$, however, Africans were not correlated with either genotype (OR $=1.24,95 \%$ CI:0.94-1.64, $P=0.636$ ). In the dominant model, with TT 
genotype reference, mutation homozygous CC genotype was evaluated and discussed with PC susceptibility. Metaanalysis was conducted with a random effects model $\left(\mathrm{I}^{2}=\right.$ $59.8, P=0.001)$, CC genotype in overall population was more inclined to $\mathrm{PC}$ than people with TT genotype $(\mathrm{OR}=$ $1.21,95 \% \mathrm{CI}: 1.01-1.44, P=0.000)$. The result in different races was consistent with allele model that there was the remarkable relationship in European or Asian populations, but no correlation in African populations (Europeans, OR $=1.26,95 \%$ CI:1.01-1.58, $P=0.001$; Asians, OR $=1.05$, 95\% CI:0.72-1.52, $P=0.003$; Africans, OR $=1.52,95 \%$ CI:0.86-2.69, $P=0.669$ ). Other models (CCvsCT+TT, $\mathrm{CC}+\mathrm{CTvsTT}$, CTvsTT) were not heterogeneous among different races, either.

\section{Allele frequency of $E S R a r s 9340799, r s 2234693$ and comparing to the 1000 genome population}

In Table 3, we demonstrated the distinct difference of allele frequencies in Caucasian, Asian and African populations in the meta-analysis of ESR $\alpha$ rs9340799 and rs2234693, which were consistent with the data of 1000 genome population project, European ancestry (EUR), Asian ancestry (EAS), African ancestry (AFR).

\section{Publication bias and sensitivity analysis}

Begg's funnel plot and Egger's test were performed to estimate publication bias. As shown in Figures 4 and Figure 5, the funnel plots presented scattered distribution but large symmetry, indicating that there was no obvious evidence of publication bias in ESR $\alpha$ rs9340799 (AvsG $P=0.081$, AAvsGG, $P=0.111)$ and $\mathrm{ESR} \alpha$ rs2234693
(Cvst, $P=0.166$, CCvsTT, $P=0.136$ ). In addition, we conducted sensitivity analysis to assess the stability of meta-analysis between ESR $\alpha$ rs2234693 and PC risk. As shown in Figure 6 and Figure 7, there was no significant difference, suggesting that articles selected in this research were available.

\section{DISCUSSION}

$\mathrm{ESR} \alpha$ is a kind of ligand-activated nuclear transcription factor and mainly distributes at the clearance between the basal epithelial cells and the matrix of the prostate. The gene coded ESR $\alpha$ was located at $6 \mathrm{q} 25.1$ of the human chromosome, which possessed 140,000 bp and consisted of eight exons and seven introns. Two of the most common polymorphic sites in ESR $\alpha$ were rs9340799 and rs2234693, both of which were situated in the first intron with $50 \mathrm{bp}$ of distance, the same as the positive chromosome area using large-scale genetic scanning chain analysis as reported previously [37]. The first intron lied at the end of amidogen, which was located in the main transcriptional domain, and contained the major adjustment sequences such as promoters and enhancers. Base $\mathrm{T} / \mathrm{C}$ or $\mathrm{A} / \mathrm{G}$ substitution in the area may cause the loss of existed restriction enzyme site and produce a new one instead, and each behavior may lead to the error splicing and bring abnormal expression products. In addition, estrogen wouldn't work without combining with $\mathrm{ESR} \alpha$, and the abnormal $\mathrm{ESR} \alpha$ expression would directly induce the ultimate physiological effect of the estrogen in body, and finally affect the occurrence and development of PC. Therefore, it is likely that the genetic polymorphisms at ESR $\alpha$ rs9340799 and rs2234693 may contribute to the risk of PC.

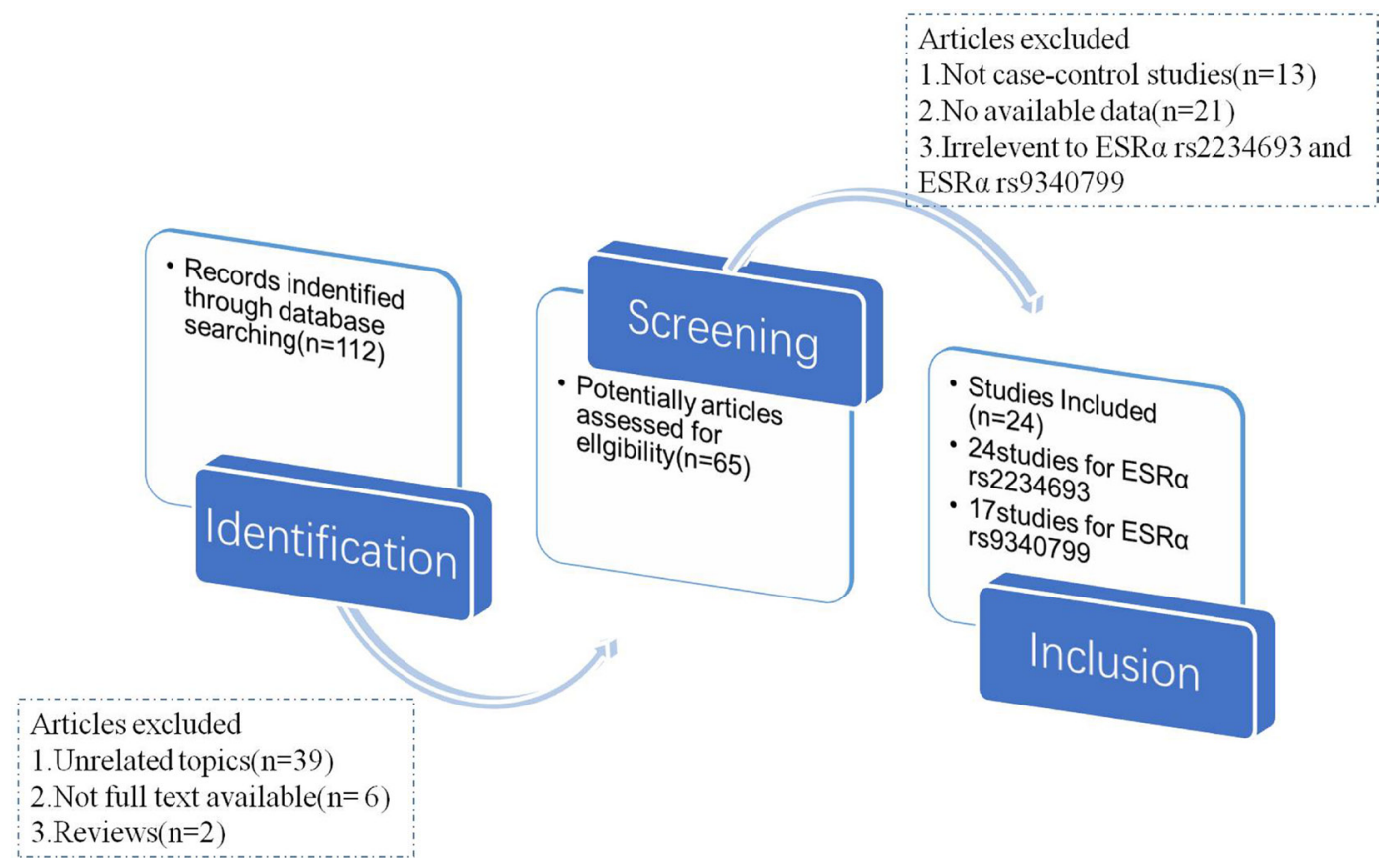

Figure 1: The flow chart of article selected in meta-analysis. 
Table 1: The main characteristics of all eligible studies in meta-analysis

\begin{tabular}{|c|c|c|c|c|c|c|c|c|c|c|c|c|}
\hline \multirow[b]{3}{*}{1} & \multirow{2}{*}{\multicolumn{2}{|c|}{$\begin{array}{l}\text { Study } \\
\text { ESR } \alpha \text { rs9340799 }(A>G)\end{array}$}} & \multicolumn{2}{|c|}{$\begin{array}{c}\text { Sample size } \\
\text { (case/ } \\
\text { control) }\end{array}$} & \multicolumn{3}{|c|}{$\begin{array}{c}\text { Genotype } \\
\text { Distribution (case) }\end{array}$} & \multicolumn{3}{|c|}{$\begin{array}{c}\text { Genotype } \\
\text { Distribution (control) }\end{array}$} & \multirow[t]{2}{*}{ Ethnicity } & \multirow[t]{2}{*}{$\begin{array}{c}\text { HWE } \\
p \text {-value }\end{array}$} \\
\hline & & & & & $\mathrm{AA}$ & $\mathrm{AG}$ & GG & \multirow{2}{*}{$\begin{array}{l}\text { AA } \\
116\end{array}$} & \multirow{2}{*}{$\begin{array}{c}\mathrm{AG} \\
93\end{array}$} & \multirow{2}{*}{$\begin{array}{c}\mathrm{GG} \\
28\end{array}$} & & \\
\hline & Modugno & 2001 & 82 & 237 & 34 & 38 & 10 & & & & Caucasian & 0.175 \\
\hline 2 & Suzuki & 2003 & 101 & 114 & 72 & 24 & 5 & 75 & 30 & 9 & Asian & 0.147 \\
\hline 3 & Fukatsu & 2004 & 117 & 242 & 74 & 37 & 6 & 163 & 68 & 11 & Asian & 0.286 \\
\hline 4 & Hernandez(a) & 2006 & 120 & 303 & 56 & 51 & 13 & 153 & 119 & 31 & Caucasian & 0.274 \\
\hline 5 & Hernandez(b) & 2006 & 431 & 582 & 182 & 191 & 58 & 229 & 281 & 72 & Caucasian & 0.371 \\
\hline 6 & Hernandez(c) & 2006 & 47 & 213 & 17 & 25 & 5 & 117 & 77 & 19 & African & 0.226 \\
\hline 7 & Cunningham & 2007 & 918 & 487 & 370 & 417 & 121 & 189 & 227 & 71 & Caucasian & 0.847 \\
\hline 8 & Beuten(a) & 2009 & 82 & 209 & 37 & 36 & 9 & 118 & 78 & 13 & African & 1 \\
\hline 9 & Beuten(b) & 2009 & 195 & 371 & 91 & 84 & 20 & 224 & 88 & 59 & Caucasian & 1 \\
\hline 10 & Beuten(c) & 2009 & 609 & 843 & 258 & 277 & 74 & 335 & 393 & 115 & Caucasian & 1 \\
\hline 11 & Gupta & 2010 & 157 & 170 & 71 & 75 & 11 & 87 & 72 & 11 & Asian & 0.565 \\
\hline 12 & Sissung & 2010 & 129 & 127 & 42 & 69 & 18 & 58 & 61 & 8 & Caucasian & 0.146 \\
\hline 13 & Balistreri & 2011 & 50 & 47 & 34 & 13 & 3 & 42 & 4 & 1 & Caucasian & 0.156 \\
\hline 14 & Szendroi & 2011 & 205 & 101 & 35 & 111 & 59 & 29 & 54 & 18 & Caucasian & 0.545 \\
\hline 15 & Safarinejad & 2012 & 162 & 324 & 20 & 108 & 34 & 81 & 187 & 56 & Caucasian & 0.05 \\
\hline 16 & Jurecekova & 2013 & 311 & 256 & 110 & 145 & 56 & 119 & 105 & 32 & Caucasian & 0.259 \\
\hline 17 & Han & 2017 & 244 & 222 & 148 & 84 & 12 & 142 & 70 & 10 & Asian & 0.68 \\
\hline & ESRa rs22346 & $3(\mathrm{C}>\mathrm{T})$ & & & $\mathrm{CC}$ & CT & TT & $\mathrm{CC}$ & CT & TT & & \\
\hline 1 & Modugno & 2001 & 81 & 237 & 21 & 34 & 26 & 43 & 109 & 85 & Caucasian & 0.424 \\
\hline 2 & Tanaka & 2003 & 115 & 200 & 29 & 63 & 23 & 48 & 113 & 39 & Asian & 0.088 \\
\hline 3 & Suzuki & 2003 & 101 & 114 & 12 & 43 & 46 & 26 & 59 & 29 & Asian & 0.851 \\
\hline 4 & Fukatsu & 2004 & 116 & 238 & 22 & 57 & 37 & 47 & 110 & 81 & Asian & 0.427 \\
\hline 5 & Hernandez(a) & 2006 & 120 & 303 & 18 & 55 & 47 & 43 & 131 & 129 & Caucasian & 0.318 \\
\hline 6 & Hernandez(b) & 2006 & 431 & 582 & 100 & 216 & 115 & 132 & 296 & 154 & Caucasian & 0.679 \\
\hline 7 & Hernandez(c) & 2006 & 47 & 213 & 16 & 22 & 9 & 50 & 113 & 50 & African & 0.413 \\
\hline 8 & Low & 2006 & 75 & 158 & 21 & 41 & 13 & 25 & 84 & 49 & Caucasian & 0.329 \\
\hline 9 & Cunningham & 2007 & 924 & 489 & 213 & 454 & 257 & 120 & 249 & 120 & Caucasian & 0.718 \\
\hline 10 & Berndt & 2007 & 470 & 603 & 111 & 238 & 121 & 135 & 316 & 152 & Caucasian & 0.254 \\
\hline 11 & Kjaergaard & 2007 & 116 & 4005 & 26 & 55 & 35 & 830 & 1972 & 1203 & Caucasian & 0.676 \\
\hline 12 & Sobti & 2008 & 157 & 170 & 52 & 77 & 28 & 64 & 90 & 16 & Asian & 1 \\
\hline 13 & Onsory & 2008 & 100 & 100 & 18 & 54 & 28 & 10 & 48 & 42 & Asian & 0.656 \\
\hline 14 & Beuten(a) & 2009 & 82 & 209 & 23 & 41 & 18 & 50 & 105 & 54 & African & 1 \\
\hline 15 & Beuten(b) & 2009 & 195 & 514 & 28 & 92 & 75 & 82 & 246 & 186 & Caucasian & 1 \\
\hline 16 & Beuten(c) & 2009 & 609 & 843 & 138 & 304 & 167 & 200 & 421 & 222 & Caucasian & 1 \\
\hline
\end{tabular}




\begin{tabular}{llccccccccccc}
17 & Gupta & 2010 & 157 & 170 & 28 & 77 & 52 & 16 & 90 & 64 & Asian & 0.066 \\
18 & Sonoda & 2010 & 180 & 177 & 31 & 89 & 60 & 29 & 87 & 61 & Asian & 0.878 \\
19 & Sissung & 2010 & 128 & 126 & 28 & 75 & 25 & 20 & 60 & 46 & Caucasian & 1 \\
20 & Szendroi & 2011 & 204 & 103 & 39 & 122 & 43 & 25 & 47 & 31 & Caucasian & 0.43 \\
21 & Safarinejad & 2012 & 162 & 324 & 57 & 94 & 11 & 90 & 169 & 65 & Caucasian & 0.434 \\
22 & Jurecekova & 2013 & 311 & 256 & 79 & 154 & 78 & 49 & 126 & 81 & Caucasian & 1 \\
23 & Lu & 2015 & 352 & 352 & 94 & 191 & 67 & 97 & 175 & 80 & Asian & 0.95 \\
24 & Han & 2017 & 244 & 222 & 48 & 102 & 94 & 34 & 96 & 92 & Asian & 0.313 \\
\hline
\end{tabular}

Table 2: Meta-analysis of the association between ESR $\alpha$ rs9340799 and prostate cancer

\begin{tabular}{|c|c|c|c|c|c|c|c|}
\hline \multicolumn{2}{|l|}{ ESRa rs9340799 } & \multicolumn{3}{|c|}{ AvsG (allele model) } & \multicolumn{3}{|c|}{ AAvsGG (additive model) } \\
\hline Population & $N$ & OR $(95 \% \mathrm{CI})$ & $\mathrm{P}_{\mathrm{h}}$ & $\mathrm{P}_{\mathrm{OR}}$ & OR $(95 \% \mathrm{CI})$ & $\mathrm{P}_{\mathrm{h}}$ & $\mathrm{P}_{\mathrm{OR}}$ \\
\hline Overall & 17 & $0.84(0.75-0.94)$ & 0.002 & 0.001 & $0.77(0.61-0.97)$ & 0.038 & 0.011 \\
\hline Caucasian & 11 & $0.84(0.72-0.96)$ & 0.015 & 0.000 & $0.75(0.56-1)$ & 0.076 & 0.002 \\
\hline Asian & 4 & $0.92(0.77-1.11)$ & 0.410 & 0.493 & $0.96(0.59-1.55)$ & 0.874 & 0.736 \\
\hline African & 2 & $0.65(0.48-0.88)$ & 0.015 & 0.800 & $0.49(0.24-1)$ & 0.049 & 0.788 \\
\hline ESRa rs2234693 & & \multicolumn{3}{|c|}{ CvsT (allele model) } & \multicolumn{3}{|c|}{ CCvsTT (additive model) } \\
\hline Population & $N$ & OR $(95 \% \mathrm{CI})$ & $\mathrm{P}_{\mathrm{h}}$ & $\mathrm{P}_{\mathrm{OR}}$ & $\mathrm{OR}(95 \% \mathrm{CI})$ & $\mathrm{P}_{\mathrm{h}}$ & $\mathrm{P}_{\mathrm{OR}}$ \\
\hline Overall & 24 & $1.09(1.00-1.18)$ & 0.037 & 0.000 & $1.21(1.01-1.44)$ & 0.030 & 0.000 \\
\hline Caucasian & 13 & $1.11(1.00-1.23)$ & 0.070 & 0.004 & $1.26(1.01-1.58)$ & 0.062 & 0.001 \\
\hline Asian & 9 & $1.02(0.86-1.21)$ & 0.571 & 0.004 & $1.05(0.72-1.52)$ & 0.517 & 0.003 \\
\hline African & 2 & $1.24(0.94-1.64)$ & 0.134 & 0.636 & $1.52(0.86-2.69)$ & 0.143 & 0.669 \\
\hline
\end{tabular}

OR odd ratio, 95\% CI confidence interval, $\mathrm{P}_{\mathrm{OR}}$ value for the test of association, $\mathrm{P}_{\mathrm{h}}$ value for heterogeneity analysis.

Table 3: The allele frequency comparison between the meta-analysis and 1000 genomes project

\begin{tabular}{|c|c|c|c|c|c|c|}
\hline \multirow{3}{*}{$\frac{\text { ESR } \alpha \text { rs9340799 }}{\text { Populations }}$} & \multicolumn{4}{|c|}{ Meta-analysis (alleles frequencies) } & \multicolumn{2}{|c|}{1000 Genomes (alleles frequencies) } \\
\hline & \multicolumn{2}{|c|}{ Cases } & \multicolumn{2}{|c|}{ Controls } & \multirow[b]{2}{*}{ A } & \multirow[b]{2}{*}{$\mathrm{G}$} \\
\hline & A & G & A & G & & \\
\hline Caucasian & 0.620 & 0.380 & 0.647 & 0.353 & 0.308 EUR & 0.692 EUR \\
\hline Asian & 0.767 & 0.233 & 0.785 & 0.215 & 0.194 EAS & $0.806 \mathrm{EAS}$ \\
\hline African & 0.655 & 0.345 & 0.741 & 0.259 & 0.265 AFR & $0.735 \mathrm{AFR}$ \\
\hline All & 0.644 & 0.356 & 0.677 & 0.323 & $0.281 \mathrm{ALL}$ & $0.719 \mathrm{ALL}$ \\
\hline ESRa rs2234693 & \multicolumn{4}{|c|}{ Meta-analysis (alleles frequencies) } & \multicolumn{2}{|c|}{1000 Genomes (alleles frequencies) } \\
\hline \multirow[t]{2}{*}{ Populations } & \multicolumn{2}{|c|}{ Cases } & \multicolumn{2}{|c|}{ Controls } & & \\
\hline & $\mathrm{C}$ & $\mathrm{T}$ & $\mathrm{C}$ & $\mathrm{T}$ & $\mathrm{C}$ & $\mathrm{T}$ \\
\hline Caucasian & 0.482 & 0.518 & 0.457 & 0.543 & 0.423 EUR & 0.577 EUR \\
\hline Asian & 0.467 & 0.533 & 0.462 & 0.538 & 0.400 EAS & $0.600 \mathrm{EAS}$ \\
\hline African & 0.547 & 0.453 & 0.495 & 0.505 & 0.570 AFR & $0.430 \mathrm{AFR}$ \\
\hline All & 0.467 & 0.533 & 0.460 & 0.540 & 0.446 ALL & $0.554 \mathrm{ALL}$ \\
\hline
\end{tabular}

EUR European ancestry, EAS Asian ancestry, AFR African ancestry, ALL All individuals from phase 1 of the 1000 Genomes Project. 
So far there were four published papers [9-12] in this meta-analysis concerning the association of the polymorphisms of ESR $\alpha$ (rs9340799 or rs2234693) with PC susceptibility. However, the number of references regarding those results was unstable due to different publication period and standard for data screening. In this paper, 17 studies on ESR $\alpha$ rs9340799 and 24 studies on ESR $\alpha$ rs2234693 were included according to the strict inclusion and exclusion critiria, through searching in both
Chinese and English databases. We found that there was statistically significant difference in distribution frequency of genetic polymorphisms of ESR $\alpha$ allelic genes between cases and controls $(p<0.05)$. Further analysis on PC patients from different races indicated that both base A and AA of ESR $\alpha$ rs9340799 may increase the risk of PC in overall population, particularly in European, however, the association was not significant in the populations of Asian and African. Similarly, a remarkable correlation
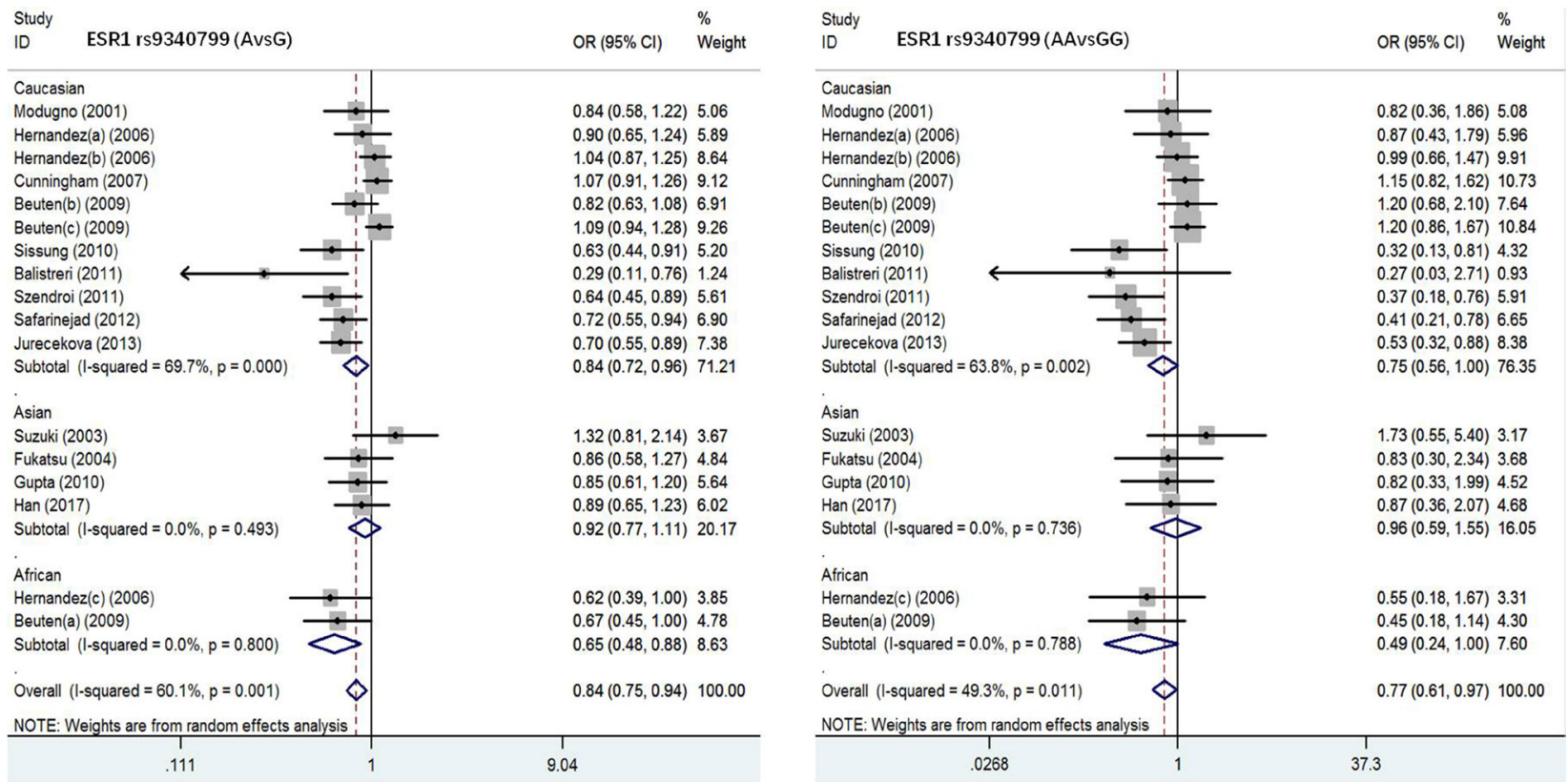

Figure 2: Forest plot of the association between ESR1 rs9340799 and prostate cancer risk(AvsG, AAvsGG).
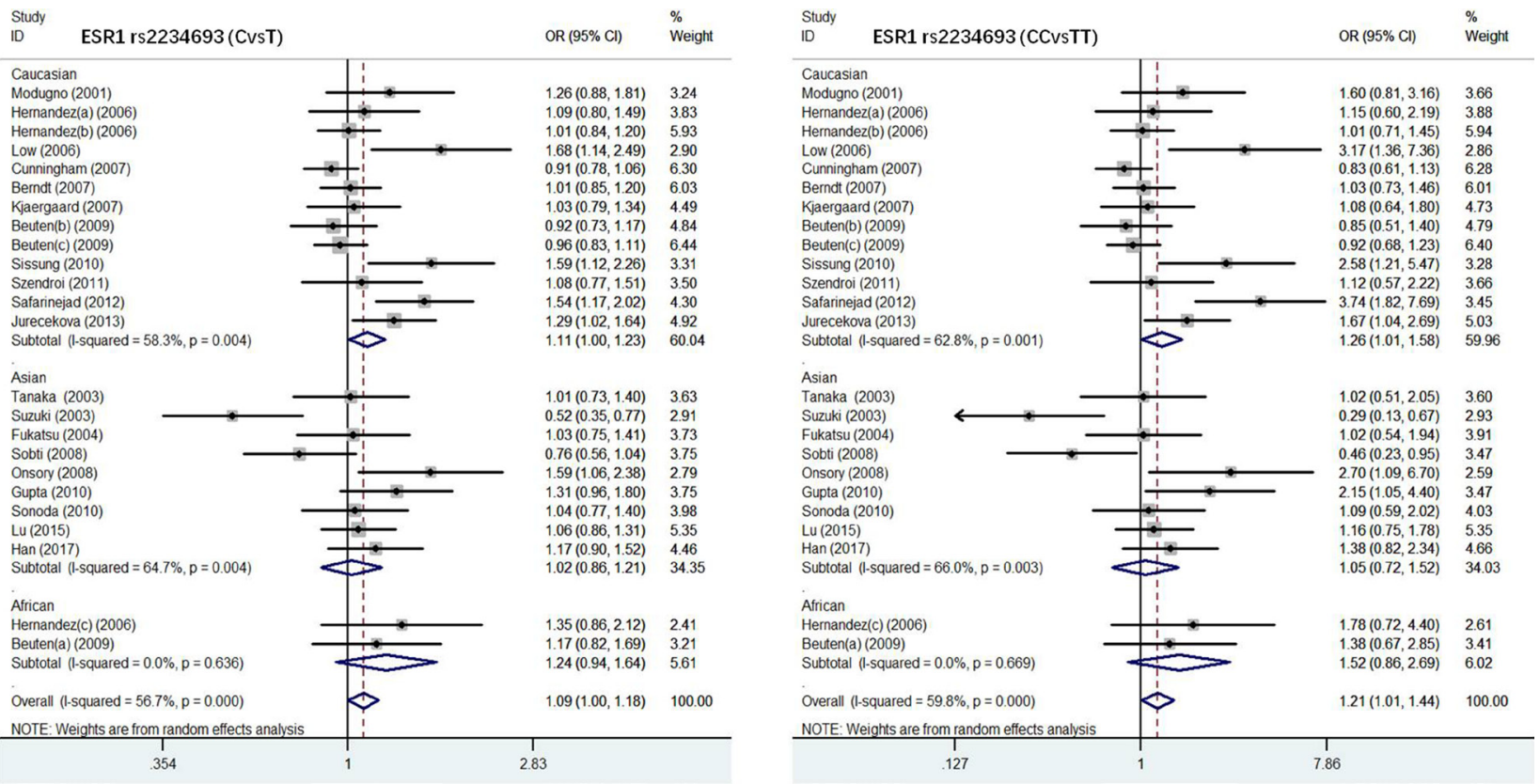

Figure 3: Forest plot of the association between ESR1 rs2234693 and prostate cancer risk(CvsT, CCvsTT). 
was found in base $\mathrm{C}$ and $\mathrm{CC}$ of $\mathrm{ESR} \alpha$ rs2234693 in Europeans and Asians, suggesting a higher risk of PC in these populations than that in Africans. Considering the limited samples from only two studies in African in this meta-analysis, studies with larger sample size including diverse ethnic populations are required to investigate the association between the polymorphisms of ESR $\alpha$ and the susceptibility of PC.

Consistent with the report of $\mathrm{Gu}$ [11], we observed that there was a certain correlation between PC and ESR $\alpha$ rs9340799, and the precision of such correlation reached to polymorphism of the site, which induced an affirmative result through further study on larger samples. Meanwhile, it should be noted that the control group of ESR $\alpha$ rs9340799 had no representativeness in the h-w genetic balance test according to the standard of $P>$ 0.05 , while it was still acceptable if the standard was $P$
$>0.01$. All results in this study were selected according to the standard of $P>0.05$, therefore, larger sample size was required in the future. Besides, different conclusions were reached in this study on the correlation between the genetic sites of ESR $\alpha$ rs2234693 and PC compared with previous studies. On the one hand, as reported before, PC was a kind of disease affected by multiple genes, which induced various clinical features. It was inevitable to reach negative results if the samples were inadequate or assigned randomly.

It is worth mentioning that there were still have several limitations in this meta-analysis: 1) For lack of linguistic experience, databases used in this study were limited to English and Chinese; 2) This study focused on the analysis on ESR $\alpha$ rs9340799 and rs2234693 only, without considering the interactions between other genes and environmental factors. Therefore, stricter design was
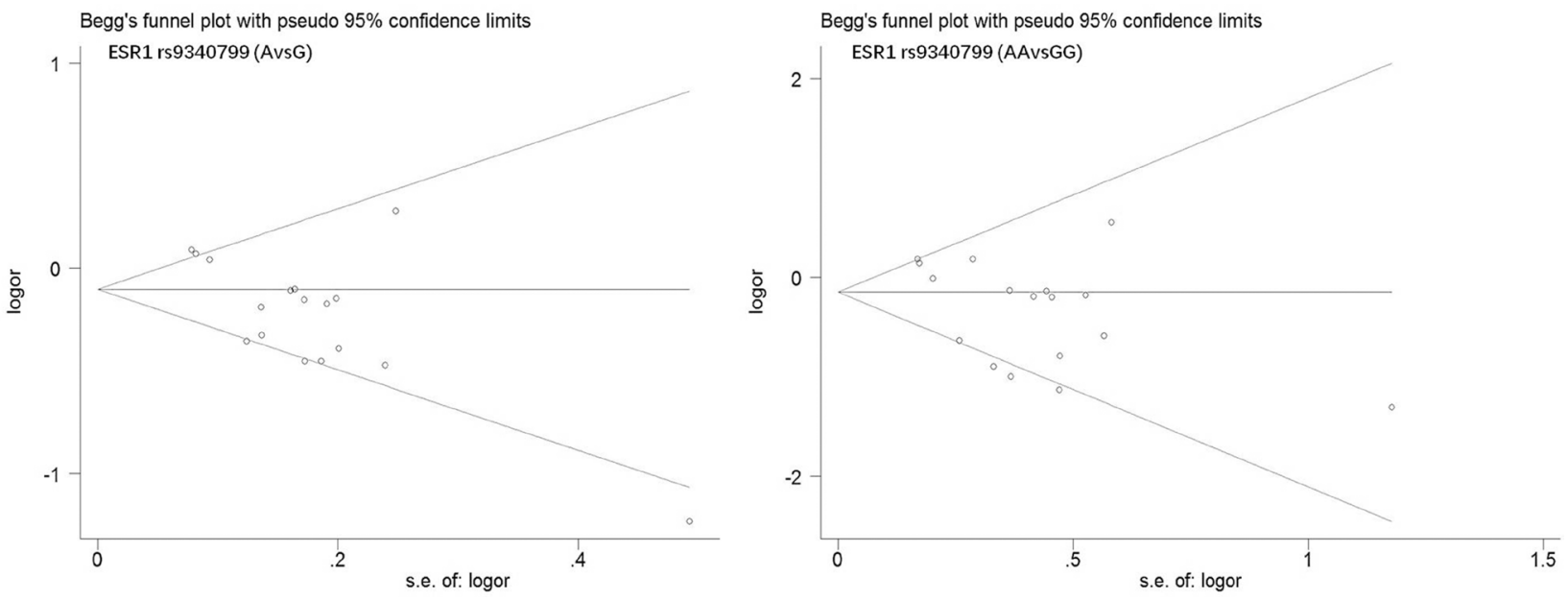

Figure 4: Begg's funnel plot of publication bias in meta-analysis of the association between ESR1 rs9340799 and prostate cancer risk(AvsG, AAvsGG).
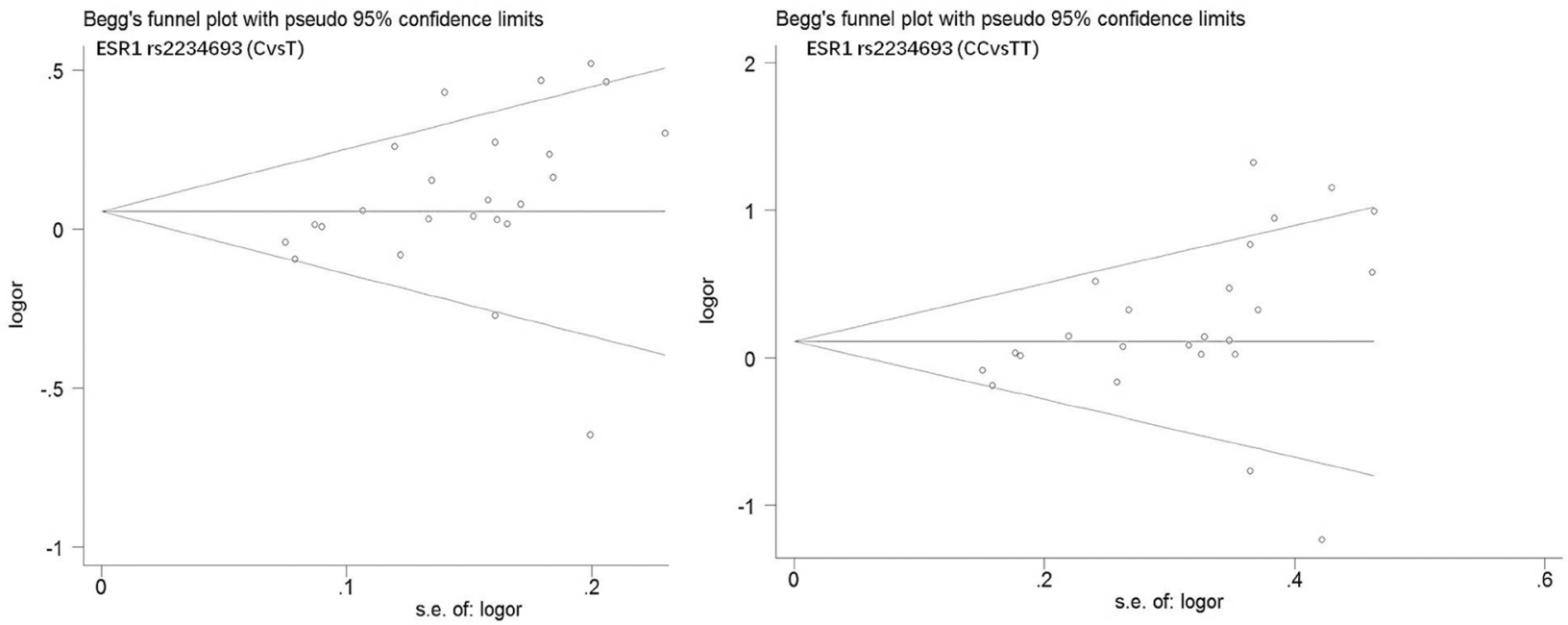

Figure 5: Begg's funnel plot of publication bias in meta-analysis of the association between ESR1 rs2234693 and prostate cancer risk(CvsT, CCvsTT). 
needed to control destructive factors, and larger samples and homogeneous cases were required in the comparable and prospective studies. At the same time, the interactions between the genes and environmental factors would be fully considered in the pathogenesis of $\mathrm{PC}$, which provided more reliable evidences for basic study and clinical treatment.

Despite the limitations, this meta-analysis revealed that ESR $\alpha$ rs9340799 and rs2234693 were associated with susceptibility to PC, and studies with larger sample size are needed to define the association between the polymorphisms of ESR $\alpha$ rs9340799 and rs2234693 and the risk of $\mathrm{PC}$ in the future.

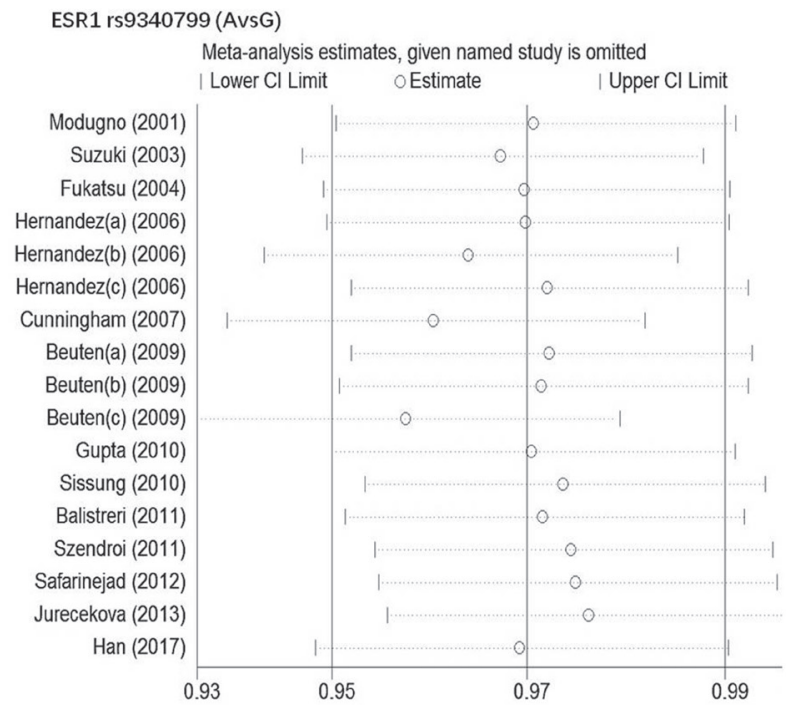

\section{MATERIALS AND METHODS}

\section{The inclusion and exclusion criteria}

Inclusion criteria: (1) the type of study was casecontrol; (2) cases were histologically diagnosed with PC patients, the pathological type was adenocarcinoma, control group was unrelated healthy people; (3) the distribution of genotypes was fully justified with HardyWeinberg genetic balance law; (4) the literature provided a complete genotype data. Exclusion criteria: (1) there was only case but without control group; (2) study which was repetitive publication; (3) incomplete data [13].

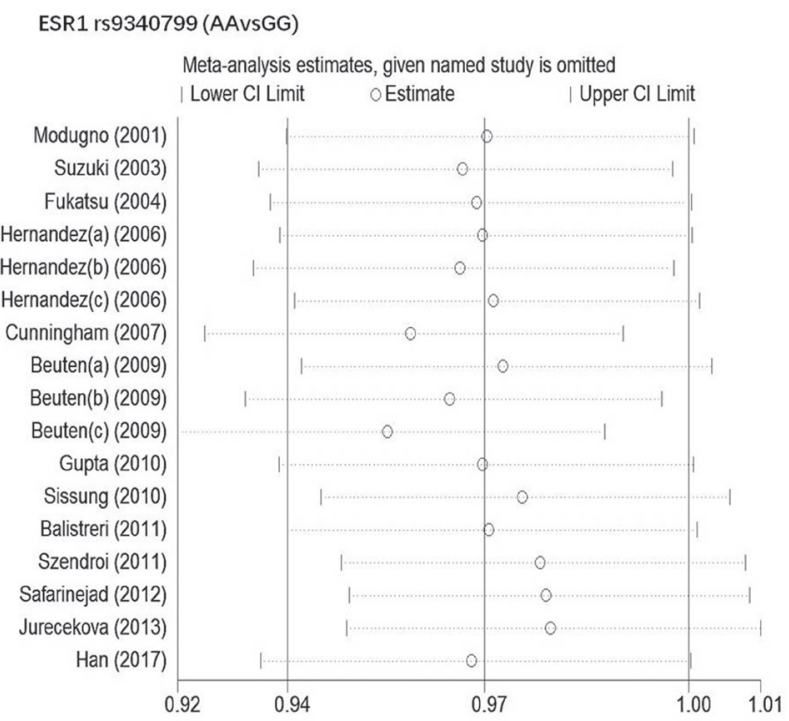

Figure 6: Sensitive analysis to assess the stability of meta-analysis between ESR1 rs9340799 and prostate cancer risk(AvsG, AAvsGG).
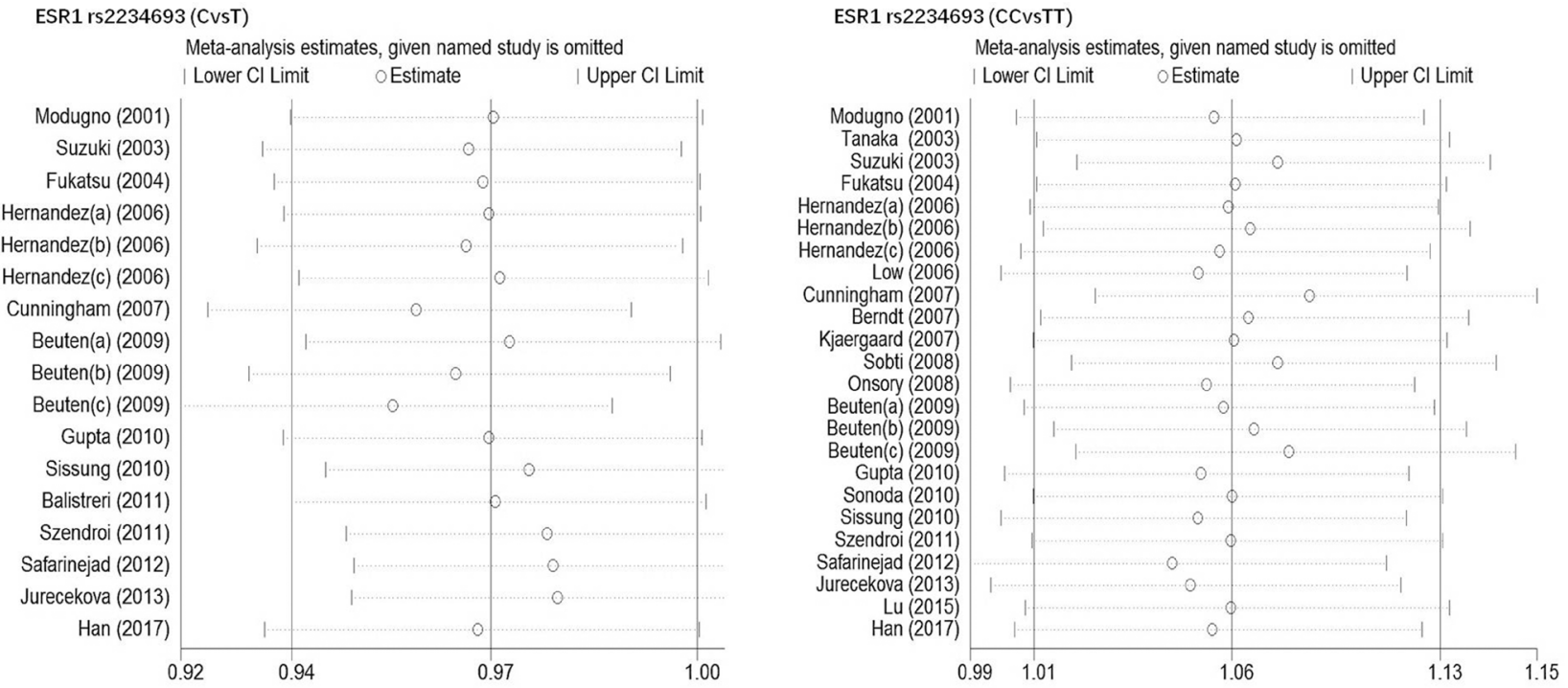

Figure 7: Sensitive analysis to assess the stability of meta-analysis between ESR1 rs2234693 and prostate cancer risk(CvsT, CCvsTT). 


\section{Literature search}

Keywords "single nucleotide polymorphism or SNP or variants", "prostate cancer or carcinoma", "estrogen receptor alpha or ESR1", were searched in PubMed, Embase, Cochrane Library, China Biology Medicine (CBM), China science and technology journal database (VIP), Chinese national knowledge infrastructure (CNKI) and Wanfang data knowledge service platform, from its inception to May 2017.

\section{Quality assessment and data selection}

Two researchers independently read abstracts, and the eligible literatures were intensively read for further study. Any differences were settled by discussion or the third researcher who decided whether be taken into the following. Quality of included reference were evaluated with Cochrane Reviewer \&s Handbook 5 System Evaluation Handbook: (1) the diagnostic criteria was clear; (2) the sample size was sufficient; (3) the case and control groups were comparable; (4) statistical analysis method was appropriate; (5) existence of bias was discussed. Each term above was recorded 1 points, $>2$ points for reliable quality. The following data was extracted from each included literature: the first author, year of publication, sample size, race, genotype frequency of case and control group, Handy-Weinberg.

\section{Statistical processing}

Meta-analysis was performed with Stata software. $Q$-test and $\mathrm{I}^{2}$-test were firstly used to judge the heterogeneity. $Q$-test $P>0.1$ or $\mathrm{I}^{2}<50 \%$ indicated that no significant heterogeneity was found between these studies, instead, fixed effect model should be used to combine. On the contrary, $Q$-test $P<0.1$ or $\mathrm{I}^{2}>50 \%$ stood for heterogeneity between these results, and such heterogeneity was not found from clinic, therefore, these data was merged using a random effect model. The combined odds ratio (OR) and $95 \%$ confidence intervals $(\mathrm{CI})$ were then calculated, and difference $(P<0.05)$ was regarded as statistical significance. Egger's and Begg 's test was applied to assess the publication bias. At last, OR value distribution was demonstrated with forest map, funnel plots and sensitive graphs, respectively.

\section{CONFLICTS OF INTEREST}

The authors declared that they have no conflicts of interest to this work.

\section{FUNDING}

This work was supported by the Chongqing Scientific Research Innovation Project (CYB16094; to G.L).

\section{REFERENCES}

1. Nelson WG, De Marzo AM, Isaacs WB. Prostate cancer. New England Journal of Medicine. 2003; 349:366-381.

2. Vanacore D, Boccellino M, Rossetti S, Cavaliere C, D'Aniello C, Di FR, Romano FJ, Montanari M, La ME, Piscitelli R. Micrornas in prostate cancer: an overview. Oncotarget. 2017; 8:50240-50251. https://doi.org/10.18632/ oncotarget.16933

3. Wu TD, Nacu S. Fast and SNP-tolerant detection of complex variants and splicing in short reads. Bioinformatics. 2010; 26:873-881.

4. Toy W, Yang S, Won H, Green B, Sakr RA, Will M, Li Z, Gala K, Fanning S, King TA. ESR1 ligand binding domain mutations in hormone-resistant breast cancer. Nature Genetics. 2013; 45:1439.

5. Terman A, Kumalska M. The effect of a SNP in ESR gene on the reproductive performance traits in Polish sows. Russian Journal of Genetics. 2012; 48:1260-1263.

6. Ioannidis JP, Ralston SH, Bennett ST, Brandi ML, Grinberg D, Karassa FB, Langdahl B, van Meurs JB, Mosekilde L, Scollen S. Differential genetic effects of ESR1 gene polymorphisms on osteoporosis outcomes. Jama. 2015; 292:2105-2114

7. Li LC, Shiina H, Deguchi M, Zhao H, Okino ST, Kane CJ, Carroll PR, Igawa M, Dahiya R. Age-dependent methylation of ESR1 gene in prostate cancer. Biochemical \& Biophysical Research Communications. 2004; 321:455-461.

8. Mcintyre MH, Kantoff PW, Stampfer MJ, Mucci LA, Parslow D, Li H, Gaziano JM, Abe M, Ma J. Prostate cancer risk and ESR1 TA, ESR2 CA repeat polymorphisms. Cancer Epidemiol Biomarkers Prev. 2007; 16:2233-2236.

9. Fu C, Dong WQ, Wang A, Qiu G. The influence of ESR1 rs9340799 and ESR2 rs1256049 polymorphisms on prostate cancer risk. Tumour Biology. 2014; 35:8319-8328.

10. Ding X, Cui FM, Xu ST, Pu JX, Huang YH, Zhang JL, Wei XD, Hou JQ, Yan CY. Variants on ESR1 and their association with prostate cancer risk: a meta-analysis. Asian Pacific Journal of Cancer Prevention Apjcp. 2012; 13:39313936.

11. Gu Z, Wang G, Chen W. Estrogen receptor alpha gene polymorphisms and risk of prostate cancer: a meta-analysis involving 18 studies. Tumor Biology. 2014; 35:5921-5930.

12. Yingdong MA, Wang A, Zhong S. A meta-analysis of rs2234693 polymorphism associated with prostate cancer risk. Chinese Journal of Pathophysiology. 2015; 31:104-108.

13. Chen Y, Li J, Mo Z. Association between the APEX1 Asp148Glu polymorphism and prostate cancer, especially among Asians: a new evidence-based analysis. Oncotarget. 2016; 7:52530 52540. https://doi.org/10.18632/oncotarget.9693.

14. Berndt SI, Chatterjee N, Huang WY, Chanock SJ, Welch R, Crawford ED, Hayes RB. Variant in sex hormone-binding globulin gene and the risk of prostate cancer. Cancer epidemiology, biomarkers \& prevention. 2007; 16:165. 
15. Beuten J, Gelfond JAL, Franke JL, Weldon KS, Crandall AC, Johnsonpais TL, Thompson IM, Leach RJ. Single and multigenic analysis of the association between variants in 12 steroid hormone metabolism genes and risk of prostate cancer. Cancer epidemiology, biomarkers \& prevention. 2009; 18:1869.

16. Chae YK, Huang HY, Strickland P, Hoffman SC, Helzlsouer K. Genetic Polymorphisms of Estrogen Receptors $\alpha$ and $\beta$ and the Risk of Developing Prostate Cancer. Plos One. 2009; 4:e6523.

17. Chen YC, Kraft P, Bretsky P, Ketkar S, Hunter DJ, Albanes D, Altshuler D, Andriole G, Berg CD, Boeing H. Sequence variants of estrogen receptor beta and risk of prostate cancer in the National Cancer Institute Breast and Prostate Cancer Cohort Consortium. Cancer epidemiology, biomarkers \& prevention. 2007; 16:1973-1981.

18. Cunningham J, Hebbring S, McDonnell SK, Cicek M, Christensen G, Wang L, Jacobsen S, Cerhan J, Blute M, Schaid D, Thibodeau S. Evaluation of genetic variations in the androgen and estrogen metabolic pathways as risk factors for sporadic and familial prostate cancer. Cancer Epidemiol Biomarkers Prev. 2007; 16:969.

19. Gupta L, Thakur H, Sobti RC, Seth A, Singh SK. Role of genetic polymorphism of estrogen receptor- $\alpha$ gene and risk of prostate cancer in north Indian population. Molecular and Cellular Biochemistry. 2010; 335:255-261.

20. Han Z, Zhang L, Zhu R, Luo L, Zhu M, Fan L, Wang G. Relationship of oestrogen receptor alpha gene polymorphisms with risk for benign prostatic hyperplasia and prostate cancer in Chinese men. Medicine. 2017; 96:e6473.

21. Hernández J, Balic I, Johnsonpais TL, Higgins BA, Torkko KC, Thompson IM, Leach RJ. Association between an estrogen receptor alpha gene polymorphism and the risk of prostate cancer in black men. Journal of Urology. 2006; 175:523-527.

22. Jurečeková J, Sivoňová MK, Evinová A, Kliment J, Dobrota D. The association between estrogen receptor alpha polymorphisms and the risk of prostate cancer in Slovak population. Molecular and Cellular Biochemistry. 2013; 381:201-207.

23. Kjaergaard AD, Ellervik C, Tybjaerghansen A, Axelsson CK, Grønholdt ML, Grande P, Jensen GB, Nordestgaard BG. Estrogen receptor alpha polymorphism and risk of cardiovascular disease, cancer, and hip fracture: crosssectional, cohort, and case-control studies and a metaanalysis. Circulation. 2007; 115:861-871.

24. Low YL, Taylor JI, Grace PB, Mulligan AA, Welch AA, Scollen S, Dunning AM, Luben RN, Khaw KT, Day NE. Phytoestrogen exposure, polymorphisms in COMT, CYP19, ESR1, and SHBG genes, and their associations with prostate cancer risk. Nutrition \& Cancer. 2006; 56:31.

25. Lu X, Yamano Y, Takahashi H, Koda M, Fujiwara Y, Hisada A, Miyazaki W, Katoh T. Associations between estrogen receptor genetic polymorphisms, smoking status, and prostate cancer risk: a case-control study in Japanese men. Environmental Health and Preventive Medicine. 2015; 20:332-337.

26. Modugno F, Weissfeld JL, Trump DL, Zmuda JM, Shea P, Cauley JA, Ferrell RE. Allelic variants of aromatase and the androgen and estrogen receptors: toward a multigenic model of prostate cancer risk. Clinical Cancer Research. 2001; 7:3092.

27. Nicolaiew N, Cancel-Tassin G, Azzouzi AR, Grand BL, Mangin P, Cormier L, Fournier G, Giordanella JP, Pouchard M, Escary JL. Association between estrogen and androgen receptor genes and prostate cancer risk. European Journal of Endocrinology. 2009; 160:101-106.

28. Onsory K, Sobti RC, Al-Badran AI, Watanabe M, Shiraishi T, Krishan A, Mohan H, Kaur P. Hormone receptor-related gene polymorphisms and prostate cancer risk in North Indian population. Molecular and Cellular Biochemistry. 2008; 314:25-35.

29. Safarinejad MR, Safarinejad S, Shafiei N. Estrogen receptors alpha (rs2234693 and rs9340799), and beta (rs4986938 and rs1256049) genes polymorphism in prostate cancer: evidence for association with risk and histopathological tumor characteristics in Iranian men. Molecular Carcinogenesis. 2012; 51:E104.

30. Sissung TM, Danesi R, Kirkland CT, Baum CE, Ockers SB, Stein EV, Venzon D, Price DK, Figg WD. Estrogen receptor $\alpha$ and aromatase polymorphisms affect risk, prognosis, and therapeutic outcome in men with castration-resistant prostate cancer treated with docetaxel-based therapy. Journal of Clinical Endocrinology \& Metabolism. 2011; 96:368-372.

31. Sobti RC, Gupta L, Singh SK, Seth A, Kaur P, Thakur H. Role of hormonal genes and risk of prostate cancer: genegene interactions in a North Indian population. Cancer Genetics \& Cytogenetics. 2008; 185:78.

32. Sonoda T, Suzuki H, Mori M, Tsukamoto T, Yokomizo A, Naito S, Fujimoto K, Hirao Y, Miyanaga N, Akaza H. Polymorphisms in estrogen related genes may modify the protective effect of isoflavones against prostate cancer risk in Japanese men. European Journal of Cancer Prevention. 2010; 19:131.

33. Sun YH, Yang B, Wang XH, Xu CL, Gao XF, Gao X, Wang LH. Study on the association between single nucleotide polymorphisms of estrogen receptor beta and the risk of prostate cancer. Chinese Journal of Surgery. 2005; 43:948-951.

34. Suzuki K, Nakazato H, Matsui H, Koike H, Okugi H, Kashiwagi B, Nishii M, Ohtake N, Nakata S, Ito K. Genetic polymorphisms of estrogen receptor alpha, CYP19, catechol-O-methyltransferase are associated with familial prostate carcinoma risk in a Japanese population. Cancer. 2003; 98:1411.

35. Tanaka Y, Sasaki M, Kaneuchi M, Shiina H, Igawa M, Dahiya R. Polymorphisms of estrogen receptor alpha in prostate cancer. Molecular Carcinogenesis. 2003; 37:202. 
36. Weibl P, Laurinc P, Tomaškin R, Bujdák P. C38 Prostate And Expectations Of Treatment -Epidemiology Research (Peter) - PART 1. European Urology Supplements. 2010; 9:629-629.
37. Nakazato H, Suzuki K, Matsui H, Ohtake N, Nakata $\mathrm{S}$, Yamanaka $\mathrm{H}$. Role of genetic polymorphisms of theRNASELgene on familial prostate cancer risk in a Japanese population. British Journal of Cancer. 2003; 89:691-696. 